\title{
All-trans and 9-cis retinoic acid alter rat hepatic stellate cell phenotype differentially
}

\author{
K Hellemans, I Grinko, K Rombouts, D Schuppan, A Geerts
}

\begin{abstract}
Background-Hepatic stellate cells exert specific functions in the liver: storage of large amounts of retinyl esters, synthesis and breakdown of hepatic extracellular matrix, secretion of a variety of cytokines, and control of the diameter of the sinusoids.

Aims-To examine the influence of alltrans retinoic acid (ATRA) and 9-cis retinoic acid (9RA) on extracellular matrix production and proliferation of activated hepatic stellate cells.

Methods-Cells were isolated using collagenase/pronase, purified by centrifugation in nycodenz, and cultured for two weeks. At this time point the cells exhibited the activated phenotype. Cells were exposed to various concentrations of ATRA and 9RA. The expression of procollagens I, III, and IV, of fibronectin and of laminin were analysed by immunoprecipitation and northern hybridisation.

Results-ATRA exerted a significant inhibitory effect on the synthesis of procollagens type I, III, and IV, fibronectin, and laminin, but did not influence stellate cell proliferation, whereas 9RA showed a clear but late effect on proliferation. 9RA increased procollagen I mRNA 1.9-fold, but did not affect the expression of other matrix proteins.

Conclusion-Results showed that ATRA and 9RA exert different, often contrary effects on activated stellate cells. These observations may explain prior divergent results obtained following retinoid administration to cultured stellate cells or in animals subjected to fibrogenic stimuli. (Gut 1999;45:134-142)
\end{abstract}

Keywords: hepatic stellate cells; retinoic acid; extracellular matrix proteins; proliferation

I Grinko

K Rombouts

A Geerts

Department of Gastroenterology,

Klinikum Stegliz, Free University of Berlin,

Germany

D Schuppan

Correspondence to: Dr K Hellemans, Laboratory for Cell Biology and Histology, Faculty of Medicine and Pharmacy, Free University of Brussels, Laarbeeklaan 103, 1090 Brussel-Jette, Belgium.

Accepted for publication 27 January 1999 myofibroblast-like cells. These activated cells proliferate rapidly and are responsible for increased production of extracellular matrix (ECM) proteins. Activation, also named transdifferentiation, of stellate cells is a central event in the pathogenesis of liver fibrosis and cirrhosis. $^{34}$

In healthy liver the most characteristic feature of stellate cells is the presence of large retinoid rich lipid droplets that are present in the cytoplasm..$^{5}$ In rats, $70-80 \%$ of the liver vitamin A reserves are found in stellate cells. ${ }^{7}$ Activation and transdifferentiation of stellate cells appear to be correlated with loss of cellular vitamin A reserves. ${ }^{8}$ Several studies have shown that the vitamin A status of the liver plays an important role in development of hepatic fibrosis. ${ }^{910}$ Vitamin A depletion appears to be a common phenomenon during human and experimental alcohol induced liver injury and fibrosis. ${ }^{11}$

The mechanisms by which retinoids modulate the phenotype of stellate cells are not yet understood. It has been suggested that retinoic acids (RA) may be important in this respect. ${ }^{12-14}$ All-trans retinoic acid (ATRA) and 9-cis retinoic acid (9RA) are biological active metabolites of vitamin A with potent biological activities towards almost all types of cells. ${ }^{15}$ RA have been shown to have a sparing effect on hepatic retinol concentrations and influence hepatic retinol secretion. ${ }^{16}{ }^{17}$ Several studies have shown that supplementation of cultured stellate cells with ATRA prevented morphological transition towards the myofibroblast-like phenotype, decreased collagen type I synthesis, and cell proliferation. ${ }^{18-20}$ During fibrogenesis and stellate cell activation, not only did the retinylester content decrease, but the concentrations of RA were also strongly reduced. ${ }^{14}$

RA modulate cell proliferation and differentiation through binding to two distinct families of transcription factors, namely retinoic acid receptors ( $\alpha, \beta$, and $\gamma$ RARs) and retinoid $\mathrm{X}$ receptors ( $\alpha, \beta$, and $\gamma$ RXRs). ${ }^{21}$ Studies on carcinoma cell lines have shown that cell behaviour could not be explained by measurement of intracellular RA concentrations, but that highly specific interactions of RA with nuclear receptors were determining factors. ${ }^{22}$ More recent studies have reported that activation of stellate cells in culture or in experimentally induced fibrosis in rats is correlated with reduced RAR $\beta$ and RXR $\alpha$ mRNAs. ${ }^{13}{ }^{14}$ On the basis of these results it has been hypothesised that stellate cell activation could be associated with diminished RA responsiveness and signalling. ${ }^{14}$

Despite evidence for the influence of RA on stellate cell transdifferentiation, complete information about the effects of ATRA and 9RA on synthesis of the main connective tissue
Abbreviations used in this paper: 9RA, 9-cis retinoic acid; ATRA, all-trans retinoic acid; BrdU, 5-bromo-2'-deoxyuridine; ECM, extracellular matrix; GFAP, glial fibrillary acidic protein; MMP, matrix metalloproteinase; RA, retinoic acid; RAR, retinoic acid receptor; RXR, retinoid X receptor; SMA, smooth muscle antibody; TGF, tumour growth factor; TIMP, tissue inhibitor of metalloproteinase. 
Table 1 Antibodies used for immunocytochemistry (ICC) and for immunoprecipitation (IP)

\begin{tabular}{|c|c|c|c|c|}
\hline & Type & Source & $\begin{array}{l}\text { Dilution for } \\
\text { ICC }\end{array}$ & Dilution for IP \\
\hline \multicolumn{5}{|l|}{ Primary antibody to } \\
\hline$\alpha$-SMA synthetic peptide & Monoclonal IgG & Sigma & $1 / 500$ & l \\
\hline Pig desmin & Monoclonal IgG & Boehringer & $1 / 10$ & 1 \\
\hline Cow GFAP & Rabbit polyclonal IgG & Dako & $1 / 2000$ & l \\
\hline Human collagen type I & Goat polyclonal AP & SBA & 1 & $1 / 40$ \\
\hline Rat collagen type III & Rabbit polyclonal AS & Schuppan et al ${ }^{61}$ & I & $1 / 75$ \\
\hline Human collagen type IV & Goat polyclonal AP & SBA & I & $1 / 75$ \\
\hline Fibronectin & Rabbit polyclonal AS & Calbiochem & l & $1 / 300$ \\
\hline Rat laminin & Rabbit polyclonal IgG & Calbiochem & I & $1 / 75$ \\
\hline \multicolumn{5}{|l|}{ Peroxidase labelled antibody to } \\
\hline Mouse IgG & Goat polyclonal AP & Amersham & $1 / 100$ & \\
\hline Rabbit IgG & Goat polyclonal AP & Jackson & $1 / 500$ & \\
\hline Goat IgG & Rabbit polyclonal AP & Jackson & $1 / 100$ & \\
\hline
\end{tabular}

GFAP, glial fibrillary protein; AP, affinity purified; AS, antiserum.

Sigma Chemie, Bornem, Belgium; Boehringer, Mannheim, Germany; Dako, Ghent, Belgium; Southern Biotechnology Associates, Birmingham, Alabama, USA; Calbiochem, La Jolla, California, USA; Amersham, Little Chalfont, UK; Jackson, West Grove, Pennsylvania, USA.

components is lacking. Furthermore, the studies looking into the antifibrotic potential of RA contain only information concerning the effect of the ATRA isomer and are restricted to examining collagen type $\mathrm{I}$ at the mRNA or protein level. The purpose of this study was therefore to investigate the influence of the two naturally occurring metabolically active RA isomers on the mRNA steady state levels and synthesis of collagen types I, III, and IV, fibronectin, and laminin by cultured stellate cells, as well as on their proliferation.

\section{Materials and methods}

ISOLATION AND CULTURE OF HEPATIC STELLATE CELLS

Adult male Wistar rats (body weight 400-500 g) were used in all experiments. The rats were treated according to the guidelines of the
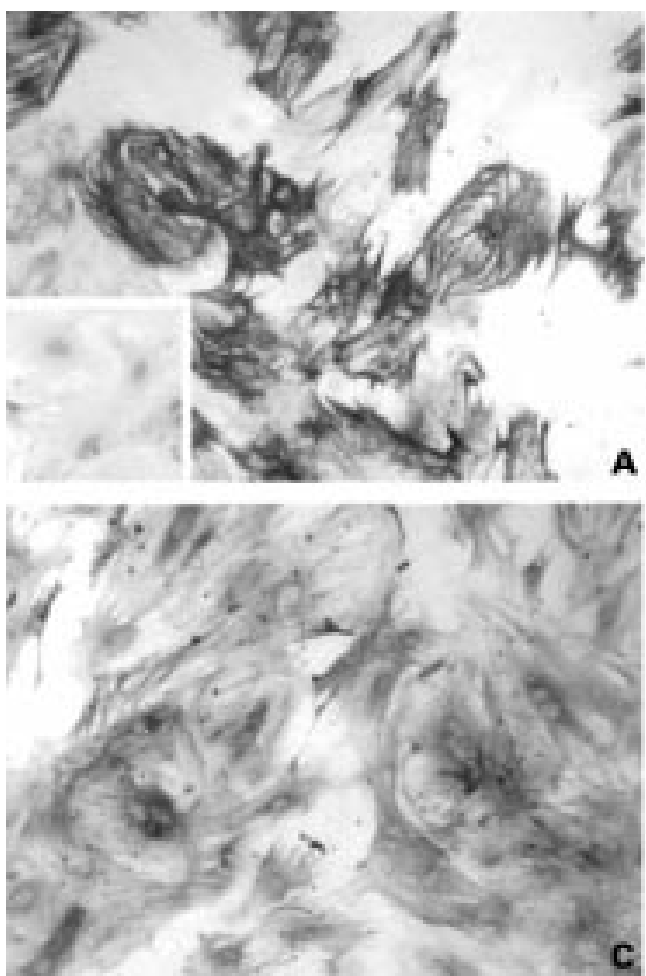

Figure 1 Immunocytochemistry of stellate cells in culture. The stellate cell origin of cultured cells was established by immunocytochemistry for desmin $(A), a S M A(B)$, and $\operatorname{GFAP}(C)$. The insert of $(A)$ shows a negative control using non-immune IgG for desmin, counterstained using haematoxylin to show nuclei. Cultured stellate cells still contained small lipid droplets that showed up when cells were exposed to excitation light of $320 \mathrm{~nm}$. Under these conditions, autofluorescence became apparent (D). Original magnification $\times 110$.
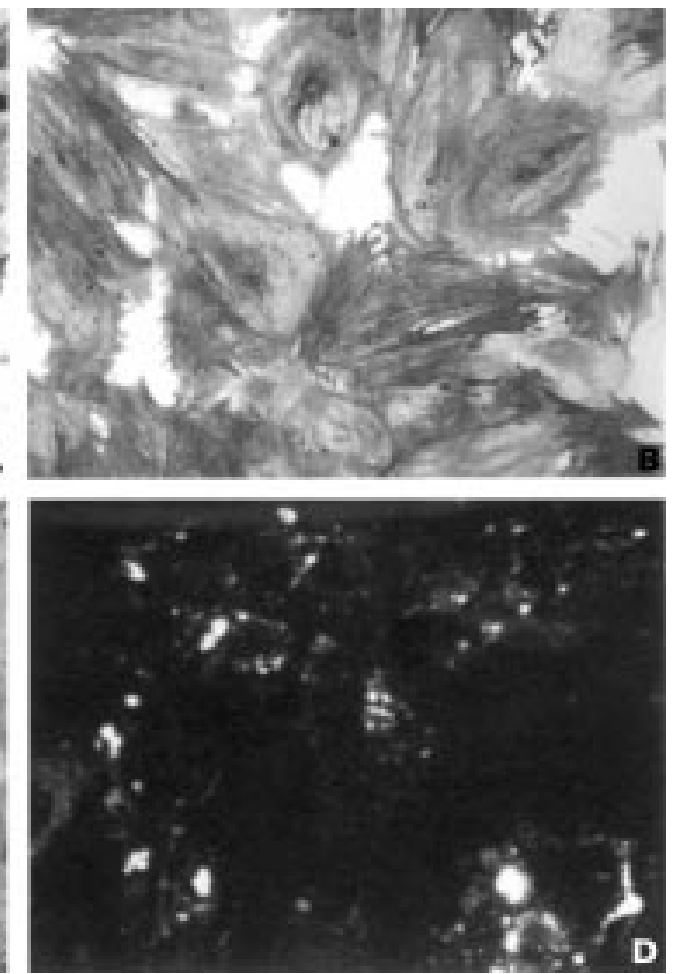

Council for International Organisations of Medical Sciences (CIOMS), as required by the Belgian National Fund for Scientific Research. Stellate cells were isolated from rats by collagenase/pronase digestion followed by density gradient centrifugation. After isolation, cells were plated at a density of $1.5 \times 10^{5}$ cells $/ \mathrm{ml}$ in $250 \mathrm{ml}$ culture flasks (Falcon, Becton Dickinson, Lincoln Park, New Jersey, USA) and maintained in Dulbecco's modified Eagle's medium (DMEM; Gibco, Paisley, Scotland, UK) with $10 \%$ fetal calf serum, 100 $\mathrm{U} / \mathrm{ml}$ penicillin, and $100 \mu \mathrm{g} / \mathrm{ml}$ streptomycin. Cell cultures were wrapped in aluminium foil and shielded from light exposure at all times. The purity of stellate cell isolates was checked by vitamin A autofluorescence and phase contrast microscopy. ${ }^{23}$ Cultured stellate cells were 


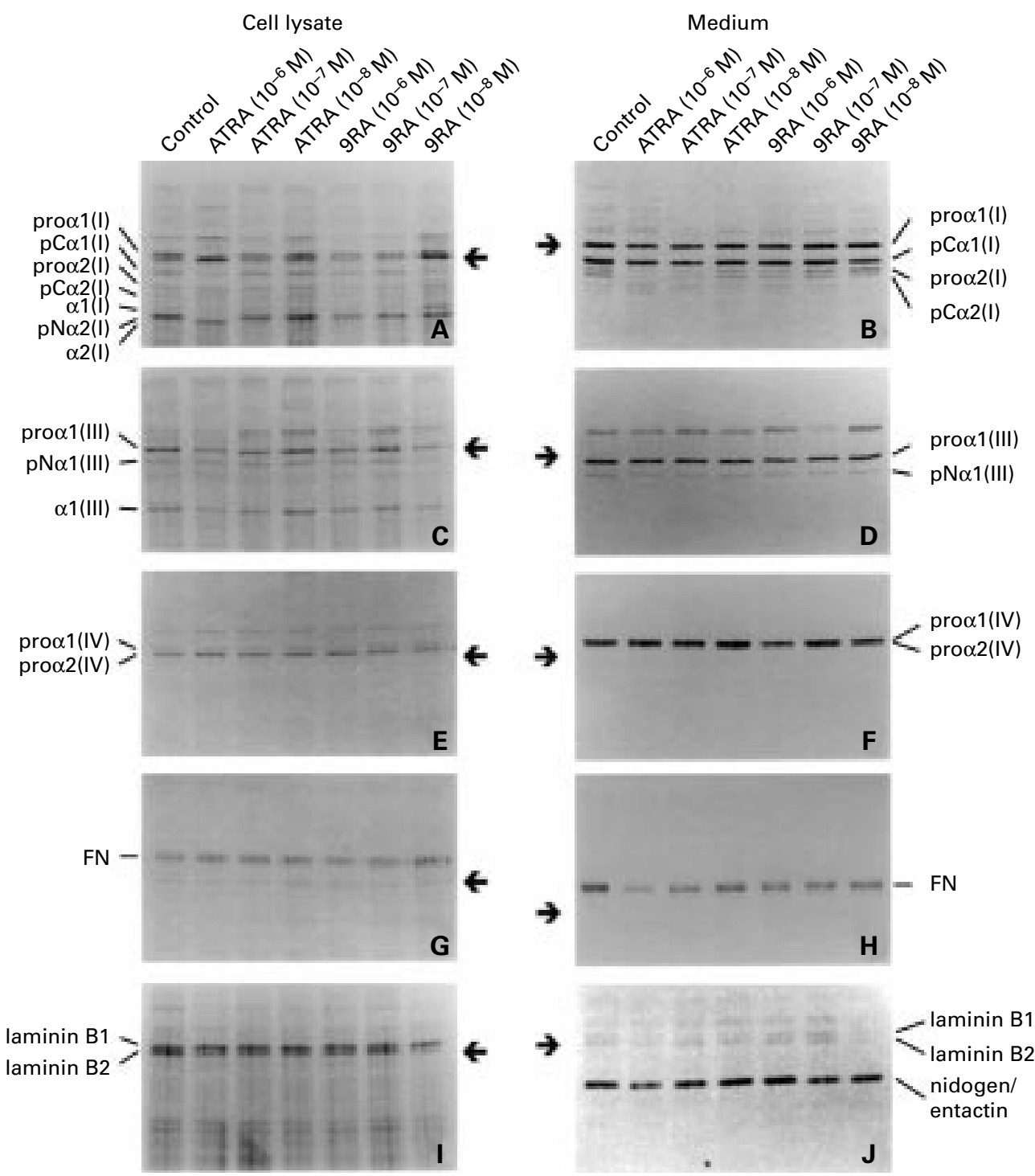

Figure 2 Representative immunoprecipitation of connective tissue proteins from media and cell lysates. Cultured stellate cells were exposed to ATRA or $9 R A$ for 48 hours and were metabolically labelled for the last 24 hours with trans ${ }^{35} S$-label $(50 \mu \mathrm{Ci} / \mathrm{ml})$. The arrows show the positions of the $205 \mathrm{kDa}$ molecular weight marker (myosin). Procollagens $\alpha 1$ (I), a1(III), and $1(I V)$, as well as fibronectin (FN) and laminin could be specifically immunoprecipitated.

allowed to reach confluency. They were then trypsinised and subcultured.

IMMUNOPHENOTYPING OF CELLS

Stellate cells cultured on Lab-Tek chamber slides for 96 hours were washed once with Gey's balanced saline solution (GBSS) $+\mathrm{Ca}^{2+}$ and fixed with cold acetone/phosphate buffered saline (PBS) $(8 / 2 \mathrm{vol} / \mathrm{vol})$ at $-20^{\circ} \mathrm{C}$ for $10 \mathrm{~min}-$ utes. Subsequently cells were washed with PBS, incubated with $2 \%$ bovine serum albumin (BSA) in PBS for 15 minutes, and reacted overnight with appropriately diluted monoclonal antibodies directed against desmin, $\alpha$ smooth muscle antibody ( $\alpha$ SMA), or glial fibrillary acidic protein (GFAP). They were washed, incubated with peroxidase labelled secondary antibody, washed, and reacted for eight minutes with $0.04 \%$ diaminobenzidine in $0.14 \mathrm{~mol} / 1$ phosphate buffer ( $\mathrm{pH} \mathrm{7.3)} \mathrm{contain-}$ ing $0.008 \%$ (vol/vol) $\mathrm{H}_{2} \mathrm{O}_{2}, 0.04 \% \mathrm{CoCl}_{2}$, and $0.032 \% \mathrm{Ni}\left(\mathrm{NH}_{4}\right)_{2}\left(\mathrm{SO}_{4}\right)_{2}$, and mounted using Aquamount (Laborimpex, Brussels,
Belgium). ${ }^{24}$ Table 1 summarises the characteristics of the antibodies used in this study.

RETINOIC ACID TREATMENT

Stellate cells were used between days 12 and 14 in culture. Cells were exposed for 48, 72, or 96 hours to $0.01,0.1$, and $1 \mu \mathrm{M}$ ATRA or 9RA (Sigma, Bornem, Belgium). Media were changed every 48 hours. For immunoprecipitations cells were kept in the presence of $50 \mu \mathrm{g} / \mathrm{ml}$ sodium ascorbate (Merck, Darmstadt, Germany) and $64 \mu \mathrm{g} / \mathrm{ml} \quad \beta$ aminopropionitrile (Sigma). Stock solutions (1 $\mathrm{mM})$ of retinoic acids in $100 \%$ ethanol were prepared and stored in vials wrapped with aluminium foil at $-70^{\circ} \mathrm{C}$. Quality of standard dilutions was checked by measuring absorption spectra (250 to 450 $\mathrm{nm}) \cdot{ }^{25}$ Dilutions in CDMEM (DMEM supplemented with $10 \%$ fetal calf serum) were freshly prepared. All manipulations of solutions and cell cultures were carried out in subdued light. Control cultures were treated with the same final concentration of ethanol ( $0.1 \%$ or less). 

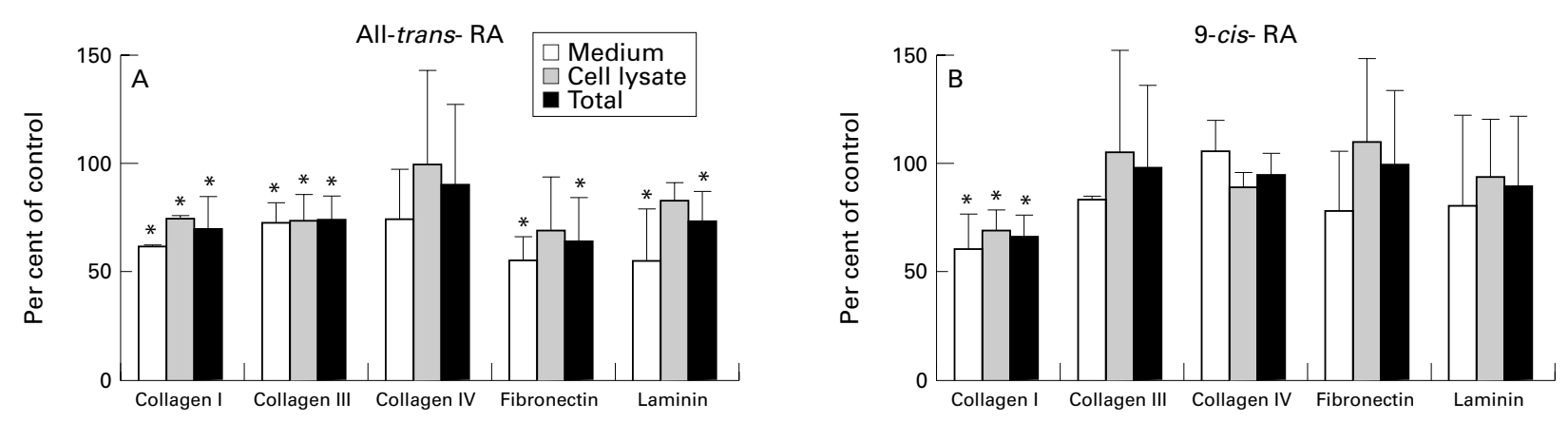

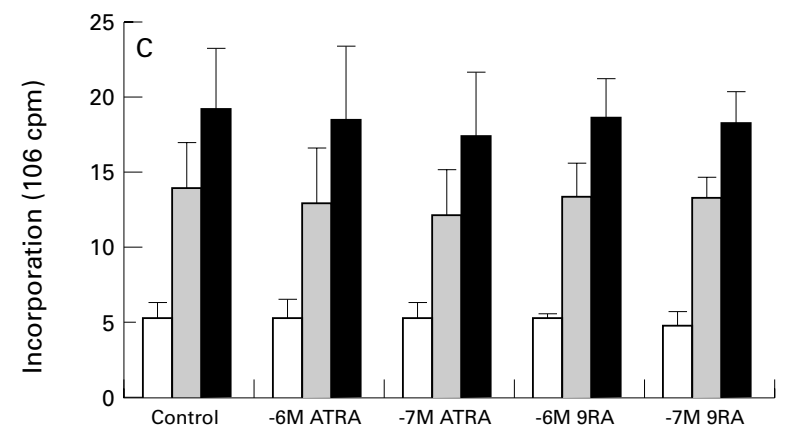

PROLIFERATION ASSAY

On day 12 , cells were trypsinised and plated in 96 well dishes $\left(5 \times 10^{4}\right.$ cells/well $)$. Cells were allowed to attach for 24 hours. At this stage, when the cells were subconfluent, they were treated for the appropriate time intervals with different concentrations of ATRA or 9RA. During the last 24 hours of the experiment, cells were labelled with $10 \mu \mathrm{M}$ 5-bromo-2'deoxyuridine (BrdU; Boehringer, Mannheim, Germany). Following fixation and denaturation of the cells, incorporation of BrdU was measured using monoclonal peroxidase conjugated antibodies directed against BrdU (Boehringer, Mannheim, Germany). Colour development was measured using a UV-VIS 3550 microplate reader (Bio-rad Laboratories, Nazareth, Belgium).

METABOLIC LABELLING AND

IMMUNOPRECIPITATION

Stellate cells were metabolically labelled during the last 24 hours of culture with $50 \mu \mathrm{Ci} / \mathrm{ml}$ ${ }^{35} \mathrm{~S}$-methionine/cysteine (trans ${ }^{35} \mathrm{~S}$-label, specific activity of ${ }^{35} \mathrm{~S}$-methionine more than $1000 \mathrm{mCi} /$ mmol; ICN Biomedicals, Costa Mesa, California, USA) in methionine free DMEM supplemented with $10 \%$ fetal calf serum, $100 \mathrm{IU} / \mathrm{ml}$ penicillin, and $100 \mu \mathrm{g} / \mathrm{ml}$ streptomycin, with or without ATRA or 9RA. After labelling radioactive medium was collected. Cells were washed twice with ice cold buffer A $(20 \mathrm{mM}$ Tris/ $\mathrm{HCl}$, $\mathrm{pH}$ 8.8, EDTA 2mM, $0.2 \mathrm{mM}$ phenylmethylsulphonyl fluoride (Sigma), and $10 \mathrm{mM}$ N-ethylmaleimide (Sigma)). The first wash was combined with the medium and centrifuged. Supernatants were stored at $-70^{\circ} \mathrm{C}$ until use. Cells were lysed with ice cold buffer A supplemented with $2 \%$ deoxycholate for 15 minutes on ice, scraped with a Teflon policeman, and collected. DNA was then sheared through a 23 gauge needle. After centrifugation, supernatants were saved, and pellets were boiled for three minutes in buffer A with $1 \%$ sodium dodecyl sulphate (SDS) and $10 \mathrm{mM}$ dithiothreitol (Fluka), followed by $25 \mathrm{mM}$ iodoacetamide (Sigma) for 30 minutes in the dark at $37^{\circ} \mathrm{C}$. This fraction was then combined with the saved supernatants, and stored at $-70^{\circ} \mathrm{C}$ until use. Protein bound cpm were determined both in medium and cell layer by hot trichloroacetic acid precipitation. Immunoprecipitations were further carried out as described previously. ${ }^{26}$ Table 1 summarises antibodies used in this experiment. Immunoprecipitation results were visualised by autoradiography and quantitated by phosphor imager analysis (Bio-rad).

NORTHERN HYBRIDISATION ANALYSIS

After exposure to RA, cells were harvested by trypsinisation and kept at $-70^{\circ} \mathrm{C}$ until RNA extraction. Total RNA extraction was performed according to Chomczynski and Sacchi. ${ }^{27}$ Total RNA (5 or $10 \mu \mathrm{g}$ ) was fractionated in a $1 \%$ agarose $/ 3 \%$ paraformaldehyde gel and transferred onto a nylon membrane (Hybond; Amersham, Little Chalfort, UK). Hybridisations were carried out as described previously. ${ }^{26}$ Probes were labeled with ${ }^{32} \mathrm{P}$ deoxycytidine triphosphate $\left({ }^{32} \mathrm{P}-\mathrm{dCTP}, 3000\right.$ $\mathrm{Ci} / \mathrm{mmol}$ ) using the Megaprime labeling kit (Amersham, Little Chalfort, UK). The probes used in this study were as described previously by Niki et al. ${ }^{26}$

\section{STATISTICS}

For immunoprecipitation, the amount of immunoprecipitable protein was calculated per dish and per $10^{6}$ cells for cell layer and medium. The values per $10^{6}$ cells for medium and cell lysate were expressed relative to the control culture; they were also combined to obtain the total radioactivity per $10^{6}$ cells. Values measured for cell layer and medium 


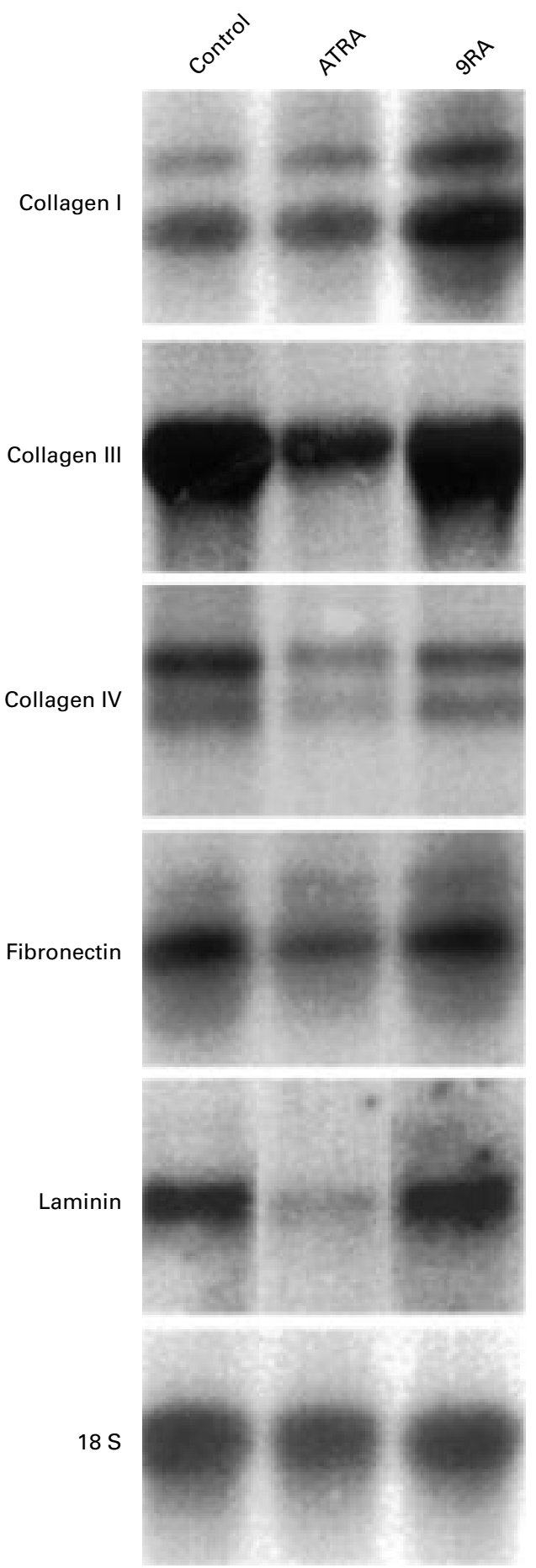

Figure 4 Representative autoradiographs of northern hybridisation experiments. Cultured stellate cells were exposed to $1 \mu \mathrm{M}$ ATRA or $9 R A$ for 48 hours.

Hybridisation was carried out with probes for procollagen $\alpha 1(I), \alpha 1(I I I I)$, and $\alpha 1(I V)$, fibronectin, laminin B1, and $18 S$ ribosomal RNA. In accordance with previous reports, ${ }^{62}$ all hybridisations provided specific signals.

were added to calculate the total effect of retinoids at the protein level. Next the ratios of treated:control were calculated. The number of observations was four for each concentration of ATRA and three for 9RA. To determine significances of the difference between controls and RA incubated cells, 95\% confidence intervals were calculated. For northern hybridisation, data were first normalised to $18 \mathrm{~S}$ ribosomal RNA, before ratios of treated:control were calculated $(n=3)$. Data were then analysed as for immunoprecipitation. All BrdU proliferation assays were done in triplicate or quadruplicate in four independent cultures. Statistical evaluation was performed by calculating the $95 \%$ confidence intervals.

\section{Results}

CHARACTERISATION OF THE CELLS

In phase contrast microscopy, stellate cells had acquired the myofibroblast-like phenotype: cells had spread extensively over the plastic substratum. The stellate cell origin of cultured cells was established by immunocytochemistry for desmin (fig 1A), ${ }^{28} \mathrm{GFAP}$ (fig 1B), ${ }^{29}$ and aSMA (fig 1C). ${ }^{30}$ Cells were strongly positive for desmin and $\alpha$ SMA. They were moderately positive for GFAP. Some cells still contained lipid droplets and, when applying fluorescence microscopy, showed weak vitamin A autofluorescence (fig 1D).

\section{IMMUNOPRECIPITATION OF CONNECTIVE TISSUE} PROTEINS

Cultured stellate cells were exposed to $1,0.1$, and $0.01 \mu \mathrm{M}$ ATRA or 9RA for 48 hours prior to analysis. During the last 24 hours of culture, the cells were metabolically labelled with ${ }^{35} \mathrm{~S}$-methionine/cysteine. Conditioned media and cell layers were collected, processed, and immunoprecipitated with specific antibodies to collagen type I, collagen type III, collagen type IV, fibronectin, and laminin. Immunoprecipitates were analysed by SDS-polyacrylamide gel electrophoresis (SDS-PAGE) and quantified by phosphor imaging. For each culture condition, the immunoprecipitable counts in medium and cell layer were calculated per culture dish and per $10^{6}$ cells. The values per $10^{6}$ cells were expressed relative to the control value.

Figure 2 shows representative immunoprecipitations for media and cell layers. We were able to immunoprecipitate specifically collagens type I, III, and IV, as well as fibronectin and laminin. Antibodies to collagen type I immunoprecipitated procollagen $\alpha 1$ (I), procollagen $\alpha 2(\mathrm{I})$, the partly processed forms $\mathrm{pC} \alpha 1(\mathrm{I}), \mathrm{pC} \alpha 2(\mathrm{I})$, and the fully processed collagen $\alpha 1(\mathrm{I})$ and collagen $\alpha 2(\mathrm{I})$ chains from cell lysate (fig $2 \mathrm{~A}$ ). In the medium only intact procollagen and $\mathrm{pC}$ collagen chains were present (fig 2B). Antibodies to the N-terminal propeptide of procollagen type III immunoprecipitated procollagen $\alpha 1$ (III), $\mathrm{pN} \alpha 1$ (III), and the fully processed $\alpha 1$ (III) chain (fig 2C). From medium, some fibronectin coimmunoprecipitated (fig 2D; upper band). However, procollagen type III and fibronectin could be clearly distinguished based on their different positions in the gel. Antibodies to collagen type IV immunoprecipitated specifically procollagen $\alpha 1$ (IV) and procollagen $\alpha 2$ (IV) chains (fig $2 \mathrm{E}, \mathrm{F})$. Antifibronectin antibodies immunoprecipitated specifically fibronectin isoforms, resulting in a slightly diffuse double band in the gels (fig $2 \mathrm{G}, \mathrm{H}$ ). Antibodies to laminin immunoprecipitated both laminin B1 and B2 chain from cell layer (fig 2I). From medium, very 


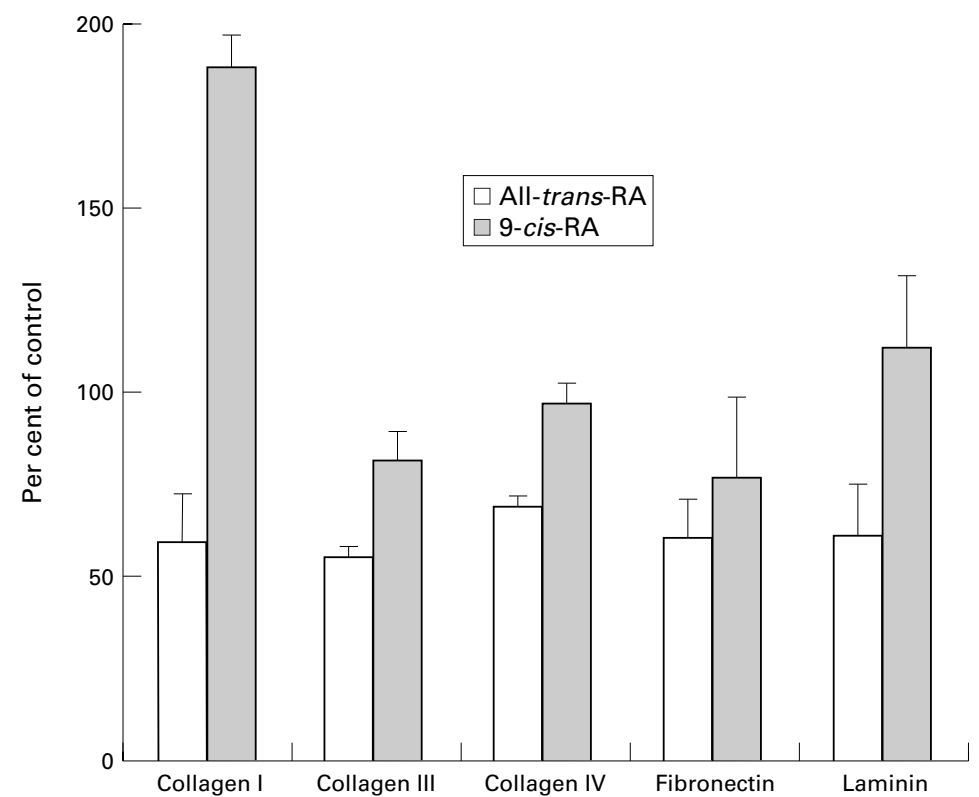

Figure 5 Northern hybridisation analysis of connective tissue protein transcripts. After normalising the signal for $18 S$ ribosomal $R N A$, the ratios of treated versus control were calculated and expressed as mean (SD).

little laminin could be precipitated. As observed by others, nidogen/entactin coimmunoprecipitated from medium (fig 2J, lower band).

For quantitative analysis, radioactivity in the specific bands on the gels was measured using phosphor imaging. Figure 3 summarises the average quantitative immunoprecipitation data on stellate cells of at least three rats. Quantitation clearly showed that both $1 \mu \mathrm{M}$ ATRA or 1 $\mu M$ 9RA suppressed collagen type I synthesis significantly $(\mathrm{p}<0.05)$. Secretion of de novo synthesised protein was decreased by 30 (15)\% in the presence of ATRA and by 34 (10)\% in the presence of 9RA respectively. Collagen $\alpha 1$ (III) synthesis was significantly affected by 1 $\mu$ M ATRA only (-26 (11)\%). Both fibronectin and laminin synthesis were reduced by $1 \mu \mathrm{M}$ ATRA, but not by the 9-cis isomer, whereas collagen $\alpha 1$ (IV) was not affected by ATRA or 9RA. Administration of $0.1 \mu \mathrm{M}$ ATRA resulted only in a significant decrease in laminin, both in cell lysate $(30(9) \%)$ and medium (20 $(11) \%)(p<0.05$, data not shown). At this concentration no effect was found on collagen synthesis. Figure 3C shows the total incorporation of trans ${ }^{35} \mathrm{~S}$-label into protein in medium, cell lysate, and medium plus cell lysate combined. These data show that administration of ATRA or 9RA did not significantly alter the cellular pool of trans ${ }^{35} \mathrm{~S}$-label, and exclude unspecific effects of ATRA or 9RA on protein labelling.

NORTHERN HYBRIDISATION ANALYSIS OF CONNECTIVE TISSUE PROTEIN TRANSCRIPTS

The immunoprecipitation experiments indicated that ATRA, and to a lesser extent 9RA, inhibited synthesis of ECM proteins by stellate cells. We therefore investigated whether these compounds acted at the transcriptional level by lowering specific mRNA levels. Cells were exposed to $1 \mu \mathrm{M}$ ATRA or 9RA for 48 hours. Figure 4 shows representative autoradiographs of the hybridisation experiments. All hybridisa-

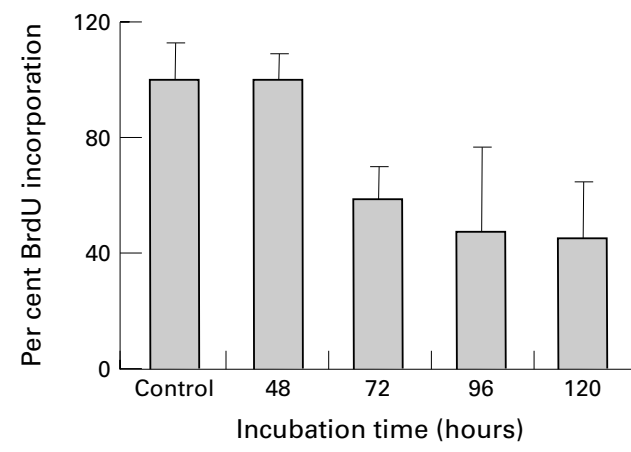

Figure 6 Effect $1 \mu M$ 9RA on BrdU incorporation by stellate cells after incubation times varying between 48 and 120 hours; representative time course experiment. Significant reduction of proliferation was found from 72 hours of treatment onward. Values are expressed as mean (SD). The number of observations was four in all cases.

tions provided specific signals. ${ }^{26}$ Hybridisation signals were quantified by phosphor imaging and normalised to the signal for $18 \mathrm{~S}$ ribosomal RNA. Data were expressed as ratios of treated versus control values.

Figure 5 illustrates the quantitative data of three independent experiments. ATRA $1 \mu \mathrm{M}$ lowered mRNA levels significantly for all investigated proteins. The strongest suppression was found for collagen $\alpha 1$ (III) mRNA $(-45(13.2) \%)$; the least suppression was found for collagen $\alpha 1$ (IV) (-31 (2.9)\%). Collagen $\alpha 1(\mathrm{I})$, fibronectin, and laminin mRNAs were reduced by approximately $40 \%$. 9RA had a very different effect on the investigated mRNA levels. Collagens type $\alpha 1$ (III) and $\alpha 1$ (IV), fibronectin, and laminin were not significantly altered. Unexpectedly, collagen $\alpha 1(\mathrm{I})$ mRNA was upregulated 1.9fold $(\mathrm{p}<0.05)$.

PROLIFERATION ASSAY

Activation of stellate cells in vivo and in vitro was characterised by enhanced proliferation of the cells. ${ }^{2}$ Therefore, we investigated the influence of ATRA and 9RA on stellate cells in culture. In preliminary experiments, we exposed cells to ATRA and 9RA for 48 hours. During the last 24 hours of culture, the cells were also incubated with BrdU. Surprisingly, we found no effect on proliferation. In order to examine whether a late effect of retinoids on stellate cells might have been overlooked, we also studied proliferation of cells after incubation times varying between 48 and 120 hours. Figure 6 shows the results of a time series experiment. It required at least 72 hours for 9RA to induce demonstrable inhibition of stellate cell proliferation. At 96 and 120 hours the effect was maximal. Therefore, the final BrdU incorporation experiments were performed with the cells exposed to retinoids for 96 hours. Figure 7 summarises the quantitative data of at least three independent experiments. 9RA $1 \mu \mathrm{M}$ and $0.1 \mu \mathrm{M}$ clearly inhibited cell proliferation $(p<0.025)$. The lower concentrations of 9RA were less inhibitory, whereas ATRA did not affect proliferation significantly. These results were confirmed by independent experiments where proliferation was measured by direct cell counting (data not shown). To exclude the 


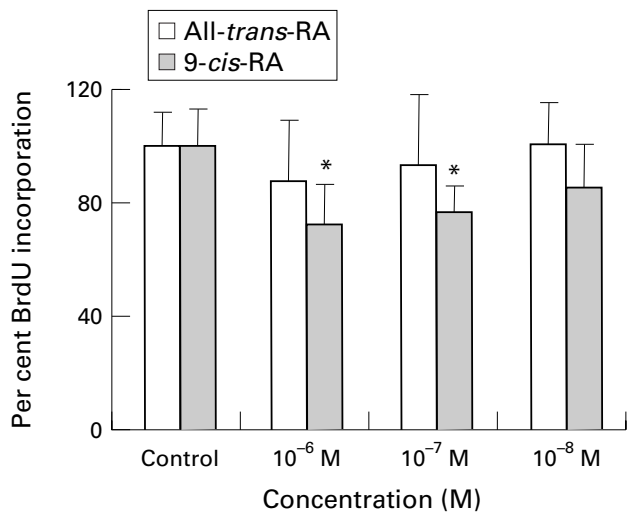

Figure 7 Effect of different concentrations of ATRA or 9RA on BrdU incorporation. Cultured stellate cells were treated for 72 hours with 1, 0.1, and $0.01 \mu M$ ATRA or 9RA. Cells were labelled for the last 24 hours with $10 \mu \mathrm{M}$ $B r d U$ solution in the presence of ATRA or 9RA. Values are expressed as mean (SD). The number of observations was four in all cases. ${ }^{*} p<0.025$.

possibility that the negative results with ATRA were the result of technical problems such as loss of active compound during incubation of the cells, we also incubated primary stellate cells at day 2 in culture for 72 hours. Using primary cells, we were clearly able to show inhibition of proliferation both by $1 \mu \mathrm{M}$ ATRA $(-45$ $(7.6) \%)$ and $1 \mu \mathrm{M} 9 \mathrm{RA}(-44(4) \%)$.

\section{Discussion}

The literature concerning the influence of retinoids on the development of hepatic fibrosis is controversial. Experimental as well as clinical studies provide conflicting results. It has been reported that low vitamin A concentrations and malnutrition enhance experimentally induced fibrogenesis. ${ }^{31}{ }^{32}$ Administration of retinol, RA, or the acyclic derivative polyprenoic acid before, during and after $\mathrm{CCl}_{4}$ treatment has been reported to inhibit the progression to and/or to enhance the regression of hepatic fibrosis. ${ }^{33-35}$

In contrast, it is well documented that chronic hypervitaminosis A leads to severe liver damage and cirrhosis in humans. ${ }^{36}$ Furthermore, vitamin A potentiates the toxic and fibrogenic effects of ethanol in rats. ${ }^{11}$ Administration of retinyl palmitate fails to protect against $\mathrm{CCl}_{4}$ induced fibrosis in mice. ${ }^{38} \mathrm{Re}-$ cently it was found that 9RA, ATRA, and the synthetic analogue E-5166, activate plasminogen, resulting in increased concentrations of active tumour growth factor $\beta$ (TGF- $\beta$ ) and increased synthesis of collagen. ${ }^{39} 40$

Experiments on isolated and cultured stellate cells added to the uncertainty about the relation between retinoids and fibrosis. Stellate cells isolated from rats pretreated with retinyl palmitate synthesised less ECM and proliferated at a slower rate than control cells. ${ }^{41}$ Incubation of activated stellate cells with retinoids resulted in a partial recovery of intracellular retinoid stores, ${ }^{42}$ a reduction in collagen type I synthesis, ${ }^{19}$ and reduced proliferation. ${ }^{12}{ }^{43} \mathrm{Re}-$ cently however, it was also shown that in stellate cell cultures, 9RA increased total and active TGF- $\beta .^{40}$ TGF- $\beta$ is known to be the most potent fibrogenic cytokine for stellate cells. ${ }^{44}$ Mediated by TGF- $\beta$, ECM synthesis may be upregulated and proliferation may be inhibited. ${ }^{45}$

Taken together, the literature does not allow firm conclusions to be drawn as to the direct effect of naturally occurring retinoids on stellate cells. Therefore we re-examined how ATRA and 9RA, two potent derivatives of vitamin A, modulate ECM synthesis and proliferation of activated stellate cells in vitro.

ATRA and 9RA acted differentially on cell proliferation, de novo protein synthesis, and ECM mRNA levels. ATRA showed a more prominent effect on de novo synthesis of ECM proteins than 9RA. ATRA significantly reduced collagens type I and III, fibronectin, and laminin, whereas the synthesis of collagen type IV was not affected. 9RA inhibited only collagen type I synthesis.

Differential effects of ATRA or 9RA were also found at the transcriptional level. ATRA significantly lowered mRNA levels for all investigated ECM proteins. Only the reduction found for procollagen type IV mRNA was not paralleled by a reduction of de novo protein synthesis. 9RA, which had no significant effect on procollagen type $\alpha 1$ (III) and $\alpha 1$ (IV), fibronectin, and laminin mRNA levels, increased collagen $\alpha 1$ (I) mRNA twofold. This result is consistent with a recent report showing that 9RA augmented collagen $\alpha 1(\mathrm{I})$, plasminogen activator, plasmin, and TGF- $\beta$ mRNA levels in activated stellate cells. ${ }^{40}$ However, our study indicated that the increased collagen $\alpha 1$ (I) mRNA was not accompanied by increased synthesis of procollagen type I protein, for which a significant reduction after treatment with 9RA was found. Apparently posttranscriptional regulatory mechanisms compensated for increased mRNA levels. Retinoids have been shown to exert direct effects on ECM turnover by modulating the production of matrix metalloproteinase 1 (MMP-1) or tissue inhibitor of metalloproteinase 1 (TIMP-1). ${ }^{46}$ Most studies with RAs, however, show downregultated MMP expression and/or increased concentrations of TIMP. ${ }^{46}{ }^{47}$ The synthesis of urokinase plasminogen activator has also been shown to be upregulated by RA in stellate cells. ${ }^{48}$ The transcription rate of the collagen $\alpha 1(\mathrm{I})$ gene is slightly higher in activated compared with primary stellate cells whereas the mRNA stability is increased 16-fold. ${ }^{49}$ 9RA could interfere directly or indirectly with the mRNA stability.

A significant reduction $(-35 \%)$ in stellate cell proliferation was found when cells were exposed to 9RA. For ATRA, although a tendency towards inhibition was observed when a concentration of $1 \mu \mathrm{M}$ was used, no significant effect was found on subcultured stellate cells. Using the same experimental set up, ATRA significantly reduced cell proliferation of primary cultures. This result conflicts with earlier reports, where inhibition of proliferation, following treatment with ATRA, was found in primary as well as in activated stellate cells. ${ }^{12}{ }^{43}$ Our results suggest that activated stellate cells become less sensitive to the antiprolif- 
erative effects of retinoic acids. Time course experiments showed that treatment of cultured cells with 9RA required at least 72 hours before inhibition of proliferation could be measured. This observation suggests that proliferation is affected by an indirect mechanism. In the same experimental setting, compounds such as histone deacetylase inhibitors exerted a measurable effect within 48 hours. ${ }^{50}$ We hypothesise that 9RA may upregulate total and active TGF- $\beta$, which in turn suppresses the proliferation of stellate cells. ${ }^{12}$

RAs modulate cell proliferation and differentiation through binding to two distinct families of transcription factors, namely RARs $(\alpha, \beta$, and $\gamma$ ) and RXRs $(\alpha, \beta$, and $\gamma) \cdot{ }^{21}$ RARs are activated both by ATRA and 9RA. RXRs are activated by $9 \mathrm{RA}$ only. ${ }^{51}$ RXRs play a central role in the complex signalling function of nuclear receptors, by forming homodimers ${ }^{52}$ and by being heterodimerisation partners for divergent nuclear receptors. ${ }^{21}$ It has been postulated that RAs and their receptors play an essential role in regulating the state of differentiation and the metabolism within stellate cells. ${ }^{40}{ }^{53}$ Specific interaction of different vitamin A metabolites with their respective receptors, might elicit divergent biological responses and could explain the fibrogenic effect of retinoids under some conditions and their antifibrogenic action under others. ${ }^{54}$

Recently stellate cells were shown to express mRNA for all RAR and RXR subtypes. ${ }^{14}$ Activation of stellate cells in prolonged culture and in experimentally induced fibrosis has been correlated with reduced RAR- $\beta$ and RXR- $\alpha$ expression. ${ }^{13}{ }^{14}$ In contrast, the concentrations of RAR- $\alpha$, RAR- $\beta$, and RXR- $\alpha$ remained unchanged after activation of primary stellate cells by a 48 hour exposure to Kupffer cell conditioned medium. ${ }^{8}$ RAR- $\alpha$ has been shown to be involved in the production of tissue plasminogen activator and activation of latent TGF- $\beta$, induced by 9,13 -di-cis-RA. ${ }^{55}$

Our results clearly showed differential effects of ATRA or 9RA administration on proliferation and ECM protein synthesis by stellate cells. This finding could possibly reflect differential interactions of the two isomers with RAR or RXR receptors and responsive genes. Transcriptional regulation of laminin gene expression by RA has already been shown. ${ }^{56}$ Recently it has been shown that inhibition of collagen $\alpha 1$ (I) mRNA expression by ATRA was mediated at the transcriptional level by RARs. ${ }^{57}$ ATRA downregulates the promoter activity of the collagen $\alpha 1$ (I) gene by decreasing binding of the RAR-RXR complex to the RARE sequence. ${ }^{58}$ Collagenase gene expression can be supressed by interaction of ATRA or 9RA with RAR and RXR..$^{59}$ Growth suppression in human carcinoma cells has been correlated with RXR-RXR activation but not by RAR-RXR. ${ }^{60}$ Recently it was shown that nuclear extracts of quiescent but not of activated cells formed high affinity complexes with RARE consensus sequences, indicating that active RAR-RXR complexes are absent in activated stellate cells. ${ }^{57}$ RAR- $\beta$ and RAR- $\gamma$ could be induced by ATRA treatment. These findings support the hypothesis that stellate cell activation is associated with diminished RA responsiveness and signalling. Further efforts will be made to reveal the RA signalling pathways in stellate cells.

In summary, we have found that ATRA and 9-cis RA exert differential effects on activated stellate cells. ATRA significantly reduces the synthesis of all investigated extracellular matrix proteins but does not affect proliferation. 9RA has a clear but late effect on proliferation and on synthesis of collagen type I, but leaves other matrix proteins unchanged. These data suggest that the two isomers regulate gene expression by different mechanisms. Thus the ratio of the various RA isoforms may determine the fibrogenic or fibrolytic properties of hepatic stellate cells.

We thank J-M Lazou for technical assistance and K Van Den Berge for the excellent photographic work. This work was made possible by FWO-V (Fonds voor Wetenschappelijk Onderzoek-Vlaanderen) grants no 3.0078.90, 9.0011.95, and G.0044.96, and OZR-VUB (Onderzoeksraad Vrije Universiteit) grants no 1933220550 and 193221120 . We are grateful to EASL for providing Dr I Grinko with the annual SEARLE fellowship

1 Mathew J, Geerts A, Burt AD. Pathobiology of hepatic stellate cells. Hepatogastroenterology 1996;43:72-91.

2 Geerts A, De Bleser P, Hautekeete ML, et al. Fat-storing (Ito) cell biology. In: Arias IM, Boyer JL, Fausto N, Jakoby WB, eds. The liver: biology and pathobiology. New York: Raven Press, 1994:819-37.

3 Gressner AM. Transdifferentiation of hepatic stellate cells (Ito cells) to myofibroblasts: a key event in hepatic fbrogenesis. Kidney Int Suppl 1996;54:S39-45.

4 Friedman SL. Hepatic stellate cells. Prog Liver Dis 1996;14: 101-30.

5 Wake K, Motomatsu K, Senoo H. Stellate cells storing retinol in the liver of adult lamprey, Lampetra japonica. Cell Tissue Res 1987;249:289-99.

6 Ito T, Nemoto J. Uber die Kupfferschen Sternzellen und die "Fettspeicherungszellen" (fat-storing cells) in der Blutkapillarenwand der menschlichen leber. Okajimas Folia Anat fpn 1952;24:243-58.

7 Blomhoff R, Norum KR, Berg T. Hepatic uptake of $\left[{ }^{3} \mathrm{H}\right]$ retinol bound to the serum retinol binding protein involves both parenchymal and perisinusoidal stellate cells. f Biol Chem 1985;260:13571-5.

8 Friedman SL, Wei S, Blaner WS. Retinol release by activated rat hepatic lipocytes: regulation by Kupffer cell-conditioned medium and PDGF. Am f Physiol 1993;264:G947-52.

9 Yamane M, Tanaka Y, Marumo F, et al. Role of hepatic vitamin $\mathrm{A}$ and lipocyte distribution in experimental hepatic min A and lipocyte distributior

10 Tanaka Y, Funaki N, Mak KM, et al. Effects of ethanol and hepatic vitamin A on the proliferation of lipocytes in regenerating rat liver. F Hepatol 1991;12:344-50

11 Leo MA, Lieber CS. hepatic vitamin a depletion in alcoholic liver injury. N Engl f Med 1982;307:597-601

2 Davis BH, Kramer RT, Davidson NO. Retinoic acid modulates rat Ito cell proliferation, collagen, and transforming growth factor beta production. F Clin Invest 1990;86:206270 .

13 Weiner FR, Blaner WS, Czaja MJ, et al. Ito cell expression of a nuclear retinoic acid receptor. Hepatology 1992;15:336-

14 Ohata $M$, Lin $M$, Satre M, et al. Diminished retinoic acid signaling in hepatic stellate cells in cholestatic liver fibrosis. Am 7 Physiol 1997;272:G589-96.

15 De Luca LM. Multiple mechanisms: the example of vitamin De Luca LM. Multiple mechanis

16 Davis BH, Vucic A. Modulation of vitamin A metabolism during hepatic and intestinal cell culture. Biochim Biophys during hepatic and intes

17 Blomhoff R, Holte K, Naess L, et al. Newly administered $\left[{ }^{3} \mathrm{H}\right]$ retinol is transferred from hepatocytes to stellate cells in liver for storage. Exp Cell Res 1984;150:186-93.

18 Davis BH, Vucic A. The effect of retinol on Ito cell proliferation in vitro. Hepatology 1988;8:788-93.

9 Sato T, Kato R, Tyson CA. Regulation of differentiated phenotype of rat hepatic lipocytes by retinoids in primary culture. Exp Cell Res 1995;217:72-83.

20 Borojevic R, Guaragna RM, Margis R, et al. In vitro induction of the fat-storing phenotype in a liver connective tissue cell line-GRX. In Vitro Cell Dev Biol 1990;26:361-8.

21 De Luca LM. Retinoids and their receptors in differentiation, embryogenesis, and neoplasia. FASEB $f$ 1991;5: tion, emb 2924 - 33 .

22 Barkai U, Sherman MI. Analyses of the interactions between retinoid-binding proteins and embryonal carcinoma cells. f Cell Biol 1987;104:671-8. 
23 Geerts A, Vrijsen R, Rauterberg J, et al. In vitro differentiation of fat-storing cells parallels marked increase in

Geerts A, Lazou JM, De Bleser P, et al. Tissue distribution, quantitation and proliferation kinetics of fat-storing cells in carbon tetrachloride-injured rat liver. Hepatology 1991;13 1193-202.

25 Furr H, Barua A, Olson J. Analytical methods. In: Sporn $\mathrm{MB}$, Roberts AB, Goodman DS, eds. The retinoids; biology, chemistry, and medicine. New York: Raven Press, 1994:179209.

26 Niki T, Schuppan D, De Bleser PJ, et al. Dexamethasone alters messenger RNA levels but not synthesis of collagens, fibronectin, or laminin by cultured rat fat-storing cells. Hepatology 1996;23:1673-81.

27 Chomczynski P, Sacchi N. Single-step method of RNA isolation by acid guanidinium thiocyanate-phenol-chloroform extraction. Anal Biochem 1987;162:156-9.

28 Yokoi Y, Namihisa T, Kuroda H, et al. Immunocytochemical detection of desmin in fat-storing cells (Ito cells). Hepatology 1994;4:709-14

29 Niki T, De Bleser PJ, Xu G, et al. Comparison of glial fibrillary acidic protein and desmin staining in normal and $\mathrm{CCl}_{4}$-induced fibrotic rat livers. Hepatology 1996;23:153845.

30 Enzan H, Himeno H, Iwamura S, et al. Immunohistochemical identification of Ito cells and their myofibroblastic transformation in adult human liver. Virchows Arch 1994;424:249-56

31 Bosma A, Seifert WF, van Thiel de Ruiter GC, et al. Alcoho in combination with malnutrition causes increased liver fibrosis in rats. $\mathcal{F}$ Hepatol 1994;21:394-402.

32 Seifert WF, Bosma A, Brouwer A, et al. Vitamin A deficiency potentiates carbon tetrachloride-induced liver fibrosis in rats. Hepatology 1994;19:193-201.

33 Senoo H, Wake K. Suppression of experimental hepatic fibrosis by administration of vitamin A. Lab Invest 1985;52: 182-94.

34 Seifert WF, Bosma A, Hendriks HF, et al. Chronic administration of ethanol with high vitamin A supplementation in
a liquid diet to rats does not cause liver fibrosis. 2 . a liquid diet to rats does not cause liver fibrosis.

35 Okuno M, Muto Y, Kato M, et al. Inhibitory effect of acyclic retinoid (polyprenoic acid) on the secretion of alphafetoprotein in $\mathrm{CCl}_{4}$-treated rats. F Nutr Sci Vitaminol Tokyo 1990;36:437-46

36 Jorens PG, Michielsen PP, Pelckmans PA, et al. Vitamin A abuse: development of cirrhosis despite cessation of vitamin A. A six-year clinical and histopathologic followup. Liver 1992;12:381-6.

37 Geubel AP, De Galocsy C, Alves N, et al. Liver damage caused by therapeutic vitamin A administration: estimate of dose-related toxicity in 41 cases. Gastroenterology 1991;100:1701-9.

38 Enzan H. Proliferation of Ito cells (fat-storing cells) in acute carbon tetrachloride liver injury. A light and electron microscopic autoradiographic study. Acta Pathol fpn 1985; 35:1301-8.

39 Koda H, Okuno M, Imai S, et al. Retinoic acid-stimulated liver stellate cells suppress the production of albumin from
parenchymal cells via TGF-beta. Biochem Biophys Res Comparenchymal cells via

40 Okuno M, Moriwaki H, Imai S, et al. Retinoids exacerbate rat liver fibrosis by inducing the activation of laten TGF-beta in liver stellate cells. Hepatology 1997;26:91321.

41 Shiratori Y, Ichida T, Geerts A, et al. Modulation of collagen synthesis by fat-storing cells, isolated from $\mathrm{CCl}_{4}{ }^{-}$or vitamin A-treated rats. Dig Dis Sci 1987;32:1281-9.

42 Troen G, Nilsson A, Norum KR, et al. Characterization of liver stellate cell retinyl ester storage. Biochem f 1994;300: $793-8$
43 Pinzani M, Gentilini P, Abboud HE. Phenotypical modulation of liver fat-storing cells by retinoids. Influence on instimulated and growth factor-induced cell proliferation. 7 Hepatol 1992;14:211-20.

44 Friedman SL. Molecular mechanisms of hepatic fibrosis and principles of therapy. F Gastroenterol 1997;32:424-30.

45 Bachem MG, Schuftan G, Schirrmacher P, et al. Feedback mechanisms between alpha $2 \mathrm{M}$ and TGF beta 1 reduce extracellular matrix synthesis of liver fat-storing cells. Ann N Y Acad Sci 1994;737:421-4.

46 Braunhut SJ, Moses MA. Retinoids modulate endothelial cell production of matrix-degrading proteases and tissue inhibitors of metalloproteinases (TIMP). 7 Biol Chem 1994;269:13472-9.

47 Numaguchi S, Okuno M, Moriwaki H, et al. Modulation of collagen synthesis and degradation by retinoids and cytokines in 3T3 L1 preadipocytes. Intern Med 1994;33: 309-16.

48 Leyland H, Gentry J, Arthur MJ, et al. The plasminogenactivating system in hepatic stellate cells. Hepatology 1996; 24:1172-8.

49 Stefanovic B, Hellerbrand C, Holick M, et al. Posttranscriptional regulation of collagen alpha1(I) mRNA in hepatic

50 Niki T, Rombouts K, De Bleser P, et al. A histone deacetylase inhibitor, trichostatin $\alpha$, suppresses myofibroblastic differentiation of rat hepatic stellate cells in primary culture. Hepatology 1998;29:858-67.

51 Levin AA, Sturzenbecker LJ, Kazmer S, et al. 9-cis retinoic acid stereoisomer binds and activates the nuclear receptor RXR alpha. Nature 1992;355:359-61.

52 Zhang XK, Lehmann J, Hoffmann B, et al. Homodimer formation of retinoid $\mathrm{X}$ receptor induced by 9 -cis retinoic acid. Nature 1992;358:587-91.

53 Sato T, Kato R, Tyson CA. Regulation of differentiated phenotype of rat hepatic lipocytes by retinoids in primary culture. Exp Cell Res 1995;217:72-83.

54 Schuppan D. Vitamin A and liver fibrosis: cure or villain? $f$ Lab Clin Med 1992;119:590-1.

55 Imai S, Okuno M, Moriwaki $\mathrm{H}$, et al. 9,13-di-cis-Retinoic acid induces the production of TPA and activation of latent TGF-beta via RAR alpha in a human liver stellate cell line, LI90. FEBS Lett 1997;411:102-6.

56 Vasios GW, Gold JD, Petkovich M, et al. A retinoic acid-responsive element is present in the 5 ' flanking region of the laminin B1 gene. Proc Natl Acad Sci USA 1989;86:9099-103.

57 Venkataramani A, Chojkier M, Houglum K. RAR-gamma mediates retinoic acid inhibition of collagen $1(\mathrm{I})$ gene expression in hepatic stellate cells [abstract]. Hepatology 1997;26(suppl):190A

58 Meisler NT, Parrelli J, Gendimenico GJ, et al. All-trans retinoic acid inhibition of Pro alpha1(I) collagen gene expression in fetal rat skin fibroblasts: identification of a retinoic acid response element in the Pro alpha1(I) collagen gene. F Invest Dermatol 1997;108:476-81.

59 Pan L, Eckhoff C, Brinckerhoff CE. Suppression of collagenase gene expression by all-trans and 9-cis retinoic acid is ligand dependent and requires both RARs and RXRs. F Cell Biochem 1995;57:575-89.

60 Wan $\mathrm{H}$, Dawson MI Hong WK, et al. Overexpressed activated retinoid $\mathrm{X}$ receptors can mediate growth inhibitory effects of retinoids in human carcinoma cells. $\mathcal{F}$ Biol Chem 1998;273:26915-22.

61 Schuppan D, Dumont JM, Kim KY, et al. Serum concentration of the aminoterminal procollagen type III peptide in the rat reflects early formation of connective tissue in experimental liver cirrhosis. F Hepatol 1986;3:27-37.

62 Geerts A, Greenwel P, Cunningham M, et al. Identification of connective tissue gene transcripts in freshly isolated parenchymal, endothelial, Kupffer and fat-storing cells by northern hybridization analysis. F Hepatol 1993;19:148-58. 